\title{
A contemporaneidade da obra "Mitológicas" de Lévi-Strauss
}

\section{The contemporaneity of the Claude Lévi-Strauss" "Mitologiques"}

\author{
Silvana Colombelli Parra Sanches ${ }^{1}$
}

\section{RESUMO}

Este artigo evidencia e analisa a atualidade da obra "Mitológicas" de Claude LéviStrauss, mais especificamente o primeiro livro "O cru e o cozido". O desencadeamento da narrativa dos mitos remete os(as) leitores(as) a um pensamento que redefine questões de alteridade e de relações sociais, como as relações entre natureza e cultura em povos não-europeus e não-ocidentais. Este tipo de discussão está na pauta do cotidiano, não só em Universidades que muitas vezes deixam de trabalhar com a graduação esta tetralogia, por considerarem de difícil leitura, mas também quando se aponta para a indústria cultural, que recentemente apresentou o filme "Avatar", de James Cameron, e que postula questões que facilmente poderiam se vincular à obra de Lévi-Strauss. Mais que uma reflexão sobre o "pensamento selvagem", a obra não está empoeirada em arcabouços distantes, mas é amarração imprescindível, tônica de discussões relevantes na academia e fora dela.

Palavras-chave: Mitologia ameríndia. Amarração. Relação Natureza-Cultura.

\section{ABSTRACT}

This article proves and analyses the significance of the Claude Lévi-Strauss' Mitologiques, paying special attention on the first book "O cru e o cozido". The unleashing of the narrative of the myths leads the readers to a thought which redefines otherness, and social relations questions, such as the relations between the nature and the culture in non-European and in non-Western peoples. This kind of discussion is in the everyday life not only in universities which very often do not work with this tetralogy in the graduation courses for considering its reading difficult, but also when we analyze the cultural industry which has recently shown the James Cameron movie's "Avatar" (2009), which raises questions that could easily be linked to Lévi-Strauss' masterpiece. More than a reflection about the "savage thought", the book is not covered with dust in distant frameworks, but it is an essential attachment, the focus of relevant discussions both in and out of the academic universe.

Key-words: Amerindian mythology. Attachment. Nature-Culture Relationship.

\footnotetext{
${ }^{1}$ Docente no Instituto de Ensino Superior da FUNLEC em Campo Grande, Mato Grosso do Sul atua no ensino de sociologia e antropologia em interface com os cursos de Artes Visuais, Educação Física e Biblioteconomia. Cientista social pela UFMS e pela UFSC, mestre em saúde coletiva pela UFMS. Email: silvanasanches48@yahoo.com.br
} 


\section{INTRODUÇÃO}

Este artigo propõe uma discussão sobre a atualidade da diversidade de mitos apresentada em Mitológicas, detendo-se a analisar Mitológicas 1: O cru e o cozido. Publicada originalmente em 1964, esta obra é um legado levistraussiano-ameríndio que se faz presente em diversos espaços, sejam eles acadêmicos ou construídos pela sociedade em geral, que buscam cada vez mais transformar visões de mundo e relações sociais baseadas em conceitos sobre as relações entre Natureza e Cultura, Modernidade e Arcaísmo, belo e grotesco, Ciência e Mito.

Aos noventa anos, Claude Lévi-Strauss, em entrevista a Beatriz PerroneMoisés (1999), dividiu seus escritos sobre mitos em "grandes mitológicas": O cru e o cozido, Do mel às cinzas, $A$ volta dos modos à mesa e o Homem nu; e, "pequenas mitológicas": A via das máscaras, A oleira ciumenta e História de Lince. As "grandes mitológicas" são compostas por 813 narrativas construídas coletivamente, pois se observa que o autor se valeu de inúmeras fontes de mitos e que tais mitos foram coletados por etnólogos em diversas etno-sociedades. Ao se tentar fazer uma imagem da obra, ou seja, percebê-la a partir de uma estética visual, pode-se dizer que os mitos, em Mitológicas, foram amarrados tridimensionalmente em um mosaico arredondado como a nossa biosfera, bem estruturados, e os nós sustentadores desta armação, que se espalham por toda parte nessas obras, são as oposições binárias.

Lévi-Strauss, em Mitológicas 1 (2004a, p.233) convenciona chamar de armação um "conjunto de propriedades que se mantêm invariantes em dois ou mais mitos". Designa o termo código a um "sistema das funções atribuídas por cada mito a essas propriedades" e confere à palavra mensagem significar o "conteúdo de um mito determinado". E, relacionando o mito bororo do "Desaninhador de pássaros" ao qual confere a característica de mito de referência - com o mito xerente da "Origem do fogo", diz que "quando se passa de um mito ao outro, a 'armação' se mantém, o 'código' se transforma e a 'mensagem' se inverte". No fazer do autor, que se aproxima do lógico-matemático, uma dinâmica relacional muito mais complexa é construída, dinâmica que une os mitos à música e à botânica. Nesse sentido, o Cru e o Cozido é dedicado à música, e a inspiração do autor está em Richard Wagner, autor de óperas que também influenciaram Friedrich Nietzsche, em $O$ nascimento da tragédia. 
Além disso, a visão cosmocêntrica ameríndia contrasta com a visão antropocêntrica que tradicionalmente guiou os rumos da ciência européia ocidental, e convida a (re)pensar o que se produziu baseado em relações fixas sobre o que seria a relação Natureza-Cultura. Lévi-Strauss (1978) em entrevistas compiladas no livro Mito e Significado, a respeito das similitudes entre os fatos narrados pelas diversas sociedades, declara:

\begin{abstract}
Assim, se o mesmo absurdo se viesse a repetir uma e outra vez, e outro tipo de absurdo também noutro local, então isso seria uma coisa que nada teria de absurdo; se fosse absurdo não voltaria a aparecer. Esta foi a minha primeira orientação, e cifrou-se em descobrir a ordem por detrás desta aparente desordem. E quando, depois de ter trabalhado nos sistemas de parentesco e nas regras de matrimônio, voltei a minha atenção, também por acaso e não por opção, para a mitologia, o problema demonstrou ser o mesmo. As histórias de caráter mitológico são, ou parecem ser arbitrárias, sem significado, absurdas, mas apesar de tudo dir-se-ia que reaparecem um pouco por toda parte. Uma criação "fantasiosa" da mente num determinado lugar seria obrigatoriamente única - não se espera encontrar a mesma criação num lugar completamente diferente. O meu problema era tentar descobrir se havia algum tipo de ordem por detrás desta desordem aparente - e era tudo. Não afirmo que haja conclusões a tirar de todo esse material. (LÉVI-STRAUSS, 1978, p.15)
\end{abstract}

Ao buscar conceituar "mito", Massaud Moisés (1974, p.300) afirma: "ingênua em relação ao tempo, a consciência mítica pressupunha uma indivisível unidade entre os seres e as coisas, entre sujeito e objeto" e, citando Georges Gusdorf (1960, p.25 apud MOISÉS, 1974, p.300) continua: "entre a sua presença em si e a presença no mundo, unidade originária da consciência e do mundo, prévia ao divórcio da re-flexão, que é desdobramento antes de ser enriquecimento". Fica implícito neste discurso, uma hierarquização positivista da consciência coletiva, quando se coloca a consciência mítica no passado, animista e "originária" a uma consciência metafísica e, posteriormente, a uma consciência que seria a científica.

Se "desdobra" antes de "enriquecer", isto é, o autor, apesar de notar que os mitos se traduzem de uma língua a outra, modificam-se com o tempo e re-significam, não vê esta dinâmica como algo já enriquecido por um pensamento complexo do real. Este pensamento contrasta com o de Lévi-Strauss, que relativiza:

Se você interrogar um índio americano, seriam muitas as chances de que a resposta fosse: uma história do tempo em que os homens e os animais ainda não eram diferentes. Porque, apesar das nuvens de tinta projetadas pela tradição judaico-cristã para mascará-la, nenhuma situação parece mais trágica, mais ofensiva ao coração e ao espírito do que a situação de uma humanidade que coexiste com outras espécies vivas sobre uma terra cuja posse partilham, e com as quais não pode comunicar-se. Compreendemos que os mitos se recusem a tomar esse defeito da criação como original; que 
vejam em sua aparição o acontecimento inaugural da condição humana e da sua fraqueza (ERIBON; LÉVI-STRAUSS, 1990, p.178). [grifos nossos]

Não apenas relativiza como insere o discurso de Lévi-Strauss nas discussões recentes sobre especismo e superação do paradigma de "dominação da natureza pelo ser-humano", por uma defesa da busca pelo equilíbrio na relação humanohumano-ambiente. Os mitos revelam uma multiplicidade de perspectivas, de visões de mundo, que não obedecem apenas à lógica do organismo e da visão humana.

Sobre isso, José Marques (2005) afirma que Lévi-Strauss procurou introduzir uma dimensão ética específica aos estudos antropológicos, que decorre, segundo o autor, de os etnólogos serem testemunhas imediatas dos males produzidos pela força modernizante da civilização ocidental. Ele escreve que: "De fato, Lévi-Strauss escreveu suas obras mais significativas ainda em plena época da empreitada colonialista européia, e é natural que sua vocação etnológica o indispusesse contra a violência exercida sobre as culturas ocidentais" (MARQUES, 2005, p.251). Ao contrário de Marques, observa-se que muitos intelectuais inseridos em contextos de destruição e desvalorização das culturas ameríndias não deploram esta realidade como Lévi-Strauss o fez, além do fato de que este poucas vezes viajou para a América do Sul e não estava em contato direto com a realidade ameríndia quando escreveu Mitológicas.

Portanto, não é natural que pessoas providas de conhecimentos etnológicos sejam mais ou menos a favor da permanência da diversidade de culturas e de espécies, outras que não sejam humanas, como aquelas que comumente inserimos cientificamente no rol da natureza. Havia uma sensibilidade incomum em uma pessoa que, em pleno maio de 68 , se preocupava com as árvores que haviam sido queimadas por estudantes em Paris.

\section{ACASOS OBJETIVOS}

Tal como Galileu Galilei, que munido de um telescópio estabeleceu relação íntima com os céus, o autor de Mitológicas 1 observou a diversidade da cultura brasileira, tanto de perto, quanto de longe. Os escritos de Lévi-Strauss receberam influência direta de teóricos como Karl Marx e Sigmund Freud, bem como de movimentos vanguardistas, como o surrealismo. Considera-se surrealismo como o 
definido por Hal Foster (2008, p.20): “Em síntesis, para mi, el surrealismo no es tanto um objeto que debemos someter a la teoria, sino um objeto teórico que produce sus próprios conceptos críticos".

Entretanto, Lévi-Strauss explica, em entrevista a Didier Eribon (1988) que os surrealistas enriqueceram e refinaram seu olhar artístico e estético em relação a objetos, que Ihe apareceram com outra luz. Estabeleceu relações de amizade com o pintor surrealista Max Ernst, que era um apaixonado por arte primitiva. Sobre a relação entre Mitológicas e a arte de Ernst, Lévi-Strauss coloca:

\begin{abstract}
Max Ernst construiu mitos particulares por meio de imagens tomadas de empréstimo a uma outra cultura: a dos velhos livros do século XIX, e ele fez estas imagens expressarem mais do que significavam quando eram vistas com um olhar ingênuo. Em Mitológicas, eu também recortei uma imagem mítica e recompus seus fragmentos para fazer com que deles brotasse mais sentido (1988, p.50). [grifo nosso]
\end{abstract}

Lévi-Strauss concebia a obra de arte como elaboração secundária ao documento científico. Segundo sua argumentação, ela ultrapassa o limite do pensamento racional e crítico, inserindo-se numa esfera mais preocupada com a estética e com as percepções imagéticas. Esta também é uma questão atual e se observa que é tema de inúmeros debates interdisciplinares sobre a racionalidade da obra de arte. Muitos críticos de arte acreditam que a arte é indecifrável e não deve ser acompanhada por análises acadêmicas sobre sua elaboração. No entanto, alguns artistas, curadores e críticos percebem a intencionalidade da obra de arte como intrinsecamente relacionada a uma visão de mundo e também a uma tomada de posição política ou teórica.

O ponto de vista de Lévi-Strauss se aproxima ao proposto por Max Ernst ao afirmar não ser criador, porque não é um deus. Neste contexto, pode-se dizer que Mitológicas é uma obra científica, inserida na linha teórica estruturalista; mas, também é uma obra de arte, pela sua capacidade estética e imagética de concatenar os mitos.

Renato Sztutman (2005), ao analisar Mitológicas 1 e 2, coloca que "bricolagem é a imagem (...) que Lévi-Strauss utiliza para se referir ao 'pensamento selvagem', aquele que escolhe pensar por meio de signos em detrimento de conceitos abstratos, ferramentas da ciência e da filosofia" (2005, p. 211). A bricolagem também é uma ferramenta indispensável no fazer contemporâneo no que se refere a obras de arte e também a produções científicas. Nas obras de arte, as 
inúmeras interferências e performances interagem artista e público, bri-colando perspectivas e tornando inusitadas as propostas artísticas. Em produções científicas, muitas vezes, têm-se uma vasta gama de autores que abordam o mesmo assunto de diferentes perspectivas e que precisam ser adensados, costurados em artigos e monografias.

Sobre as influências teóricas de Lévi-Strauss, pode-se dizer que, ao comentar com Eribon (1990) sobre Totem e tabu, de Freud, diz que este construiu um mito belo - mas inverossímil — que é o Complexo de Édipo. Lévi-Strauss atribui esta condição a uma necessidade que a maioria dos seres humanos tem de imaginar como as coisas aconteceram para tentar superar contradições. Para ele, Marx foi o primeiro a usar, sistematicamente nas Ciências Sociais, o método dos modelos. Todo O capital, conforme palavras de Lévi-Strauss, "é um modelo construído no laboratório que o autor punha a funcionar para confrontar, a seguir, os resultados com os fatos observados" (1990, p.140). Para ele, em Marx, pode-se encontrar a ideia fundamental de que se devem relacionar à mente humana as condições de sua existência prática e tentou fazer algo semelhante em Mitológicas.

Em relação ao estruturalismo que permeou toda a sua obra, Lévi-Strauss revela que nos primórdios fez um "estruturalismo ingênuo", pois o fazia sem saber. Fala da importância de Jakobson para revelar-lhe a existência de um corpo de doutrina já constituído numa disciplina, a lingüística que foi para ele, "uma iluminação". (ERIBON, LÉVI-STRAUSS, 1990, p.58)

Não obstante, apesar de ser importante mapear as influências teóricas de Lévi-Strauss, deve-se ter cautela ao associar as obras deste a essa ou aquela perspectiva. Oscar Saéz (2008) critica o modo como se analisa tal antropólogo, pois, exagera-se na medida, o que faz serem construídas várias caricaturas e nenhuma delas fiéis ao que se poderia chamar de legado inovador de Lévi-Strauss. Para Saéz "a vontade de criticar, superar, desconstruir e seguir adiante encontra muito mais incentivo nas caricaturas que nos retratos matizados dos ancestrais" (2008, p.10).

Esse último autor aprofunda a questão e enumera várias caricaturas que se faz, comumente, de Lévi-Strauss, ao criticá-lo e até ao elogiá-lo: a do antropólogo avesso à história, a daquele que fez pouco trabalho de campo, o semeador de dicotomias, o linguista, o mentalista, o formalista, o representante máximo do modernismo científico. Saéz (2008) se aventura em também apontar horizontes de percepção do que seja a obra de Lévi-Strauss: o positivista, o antipositivista e um 
que Saéz considera não menos protagonista em Mitológicas 1: o melancólico subjetivo.

Em Tristes Trópicos, o "melancólico subjetivo" é bastante presente. No capítulo A busca do poder ele prenuncia:

[...] a civilização já não é mais essa flor frágil que se preservava, que se desenvolvia a duras penas em certos recantos abrigados de um torrão rico em espécies rústicas, talvez ameaçadoras por sua vivacidade, mas que permitiam também variar e revigorar as sementeiras. A humanidade instalase na monocultura; prepara-se para produzir a civilização em massa, como a beterraba. Seu trivial só incluirá este prato (LÉVI-STRAUSS, 2004b, p.35).

Conforme análise do próprio Lévi-Strauss, em Mitológicas 1, "seja qual for o mito tomado por centro, suas variantes irradiam-se em torno dele, formando uma rosácea que se expande progressivamente e se complica". E, emenda: "seja qual for a variante colocada na periferia que escolhermos como novo centro, o mesmo fenômeno se reproduz, dando origem a uma segunda rosácea, que em parte mistura-se a ela e a transpõe" (ERIBON, LÉVI-STRAUSS, 1990, p.165). Por isso que mito de referência é diferente de mito fundador, pois para ser referência não precisa estar na origem ou ser o mais central da questão, mas sim fazer o papel de desencadeador de outros. Isso deverá acontecer, segundo o autor, até que essas construções encurvadas levem o(a) leitor(a) de novo ao ponto de onde partiu. Fala que o resultado deste exercício seria um campo de início confuso e indistinto e depois, aos poucos, desenvolver-se uma rede de linhas de força e ele se revela poderosamente organizado.

Esta metáfora de Lévi-Strauss, longe de estar ultrapassada - e sem deixar de fazer alusão ao mito europeu de posição das pétalas associada ao parentesco (LÉVI-STRAUSS, 2008), introdutório de O Pensamento Selvagem - encontra eco no pensamento de Stuart Hall que, em $A$ identidade cultural na pós-modernidade (1988), acentua diferenças entre o sujeito proposto pelo lluminismo do século XVIII, o sujeito cunhado pela sociologia do século XIX e XX e o sujeito pós-moderno. Ele coloca que:

a sociedade não é, como os sociólogos pensaram muitas vezes, um todo unificado e bem delimitado, uma totalidade, produzindo-se através de mudanças evolucionárias a partir de si mesma, como o desenvolvimento de uma flor a partir de seu bulbo. Ela está constantemente sendo 'descentrada' ou deslocada por forças fora de si mesma (HALL, 1988, p.17). 
A primeira vista parecem pensamentos destoantes, sociedade e mito, mas revelam ambas as metáforas, as identidades modernas descentradas, fragmentadas que compõe um todo. Estas identidades, míticas como no caso da análise de LéviStrauss, irradiam-se e deslocam-se de seu lugar, ora ocupando o imaginário de povos de um local do globo, ora influenciando a identidade de grupos sociais localizados em seu oposto. Para isso, corroboram os meios midiáticos, ou mais precisamente a indústria cultural, que massifica — mais ao mesmo tempo projeta reflexões díspares que permitem que culturas se conectem. No propósito de verificar diferentes noções do que seja natureza-cultura e de re-construí-las a partir de uma visão não-especista (como pretende o atual movimento ambientalista, por exemplo), essa projeção pode ser bastante benéfica.

Além de encontrar aspectos nos mitos relacionados com o cru, o podre, o mofado, o cozido, o cromático, o ruído, a algazarra, o riso, o silêncio, o incesto, etc. Lévi-Strauss, em O cru e o cozido, inseriu elementos visuais para compor poeticamente a imagem dos animais viventes no contexto das etnias sulamericanas. As ilustrações, segundo ele, "datavam de épocas em que a zoologia e a botânica não estavam divorciadas do folclore". (ERIBON, LÉVI-STRAUSS, 1990, p.218).

Nesse sentido, os rumos da ciência atual permitem que co-existam pertinentes, diferentes e divergentes propostas de visão de mundo, o que faz com que pensamentos míticos ou fabulosos sejam mais considerados e integrados ao pensamento científico do que em meados do século $X X$. Como exemplo, tem-se a medicina ensinada nas universidades, especialista e biologicista em contato permanente com disciplinas da nascente "naturologia" que reúne práticas terapêuticas pensadas e elaboradas em diferentes contextos sócio-históricos e que permite uma incursão nas mitologias de diversas culturas e na busca de distintas respostas para a promoção da saúde.

Com relação ao método, Saéz (2008) lembra que Lévi-Strauss é um autor que se utiliza de negações para construir uma teoria. E, aproxima as negações de LéviStrauss a um fazer performático e cita como exemplo a proibição ou não do incesto na análise estrutural dos mitos. Assim é possível concordar com Saéz que diz que Mitológicas 1 é uma obra que sintetiza mitos diversos, de acordo com temáticas que evocam o fazer performático, e que é próprio de um pensamento não-científico e não passível de enquadramento nos modelos rígidos da ciência européia tradicional.

Cad. de Pesq. Interdisc. em Ci-s. Hum-s., Florianópolis, v.11, n.99, p. 2-21 , jul/dez. 2010 
Apesar disso, se pode acreditar possível fazer uma leitura de Mitológicas 1 através da ciência que se abre ao pensamento mais interdisciplinar e complexo.

\section{SINFONIA DA AMARRAÇÃO}

O cru e o cozido obedece a um rito de espetáculo musical, como as óperas, e a edição brasileira de Cosac \& Naif tem cada parte iniciada por uma folha negra, o que lembra o(a) leitor(a) das cortinas do teatro que se abrem. Para Lévi-Strauss, a "grande forma musical [...] recupera as estruturas do pensamento mítico" e os "modos de pensar sempre presentes no inconsciente buscam um novo emprego" (ERIBON; LÉVI-STRAUSS, 1990, p.226), o que nos mitos era sentido, em nossa sociedade se torna som.

Ao comparar mito e música, que o autor francês se baseiam ambos em reconstruções contínuas, ele revela que: "a música destaca os aspectos do som já presentes na linguagem, enquanto a mitologia sublinha o aspecto do sentido, 0 aspecto do significado, que também está profundamente presente na linguagem” (LÉVI-STRAUSS, 1978, p.49) Sobre isso, Dorothea Passetti argumenta: "O que une música e botânica à investigação dos mitos é a dinâmica relacional entre as partes, possibilitando perceber transformações estruturais das propriedades dos objetos (os seres) e das funções significantes" (2008, p. 299).

Percebe-se assim, que o método estruturalista não é algo engessado como acreditam alguns críticos, como por exemplo, um esqueleto humano (internamente rígido) ou a carapaça de um caracol (externamente rígido). O estruturalismo é relacional e se metamorfoseia em um policromatismo ímpar. A quarta parte de $\mathrm{O}$ cru e o cozido é concluída com o sub-capítulo Peça Cromática, no qual Lévi-Strauss aproxima os conceitos ameríndios aos gregos e aos ocidentais modernos quando atribui uma certa ambigüidade ao termo que pode nos remeter à imagem do arco-íris e também a sentimentos como o sofrimento ou a traços culturais, como o luto. Em várias culturas, animais coloridos podem ser associados à vida ou à morte, pois são muito sedutores, mas também podem dispor de altas doses de veneno, o que não faz a cultura indígena mais exótica, estranha ou distante das outras.

A separação natureza-cultura, como o autor mesmo observou, serve apenas para pensar, não está dada desta maneira na realidade. Desta forma, as relações 
sociais são matéria-prima empregada para a construção dos modelos que tornam manifesta a própria estrutura social. Ele não reduz sua teoria a modelos matemáticos e, pelo contrário, coloca a vida social no domínio do aleatório e diz que na "vasta sopa empírica [...] em que a desordem impera, formam-se aqui e ali ilhotas de organização”. (ERIBON; LÉVI-STRAUSS, 1990, p.133).

Com esta "sinfonia", partiu em O cru e o cozido da hipótese de que os bororo e etnias próximas - membros da família lingüística Jê — têm organizações sociais afins, cujas diferenças podem ser interpretadas como metamorfoses que se encontram e se distanciam como a um sistema. Na tessitura de uma unidade mitológica, o autor completa: "Tomado por si só, cada detalhe não é obrigado a significar algo, porque é no seu relacionamento diferencial que reside sua inteligibilidade". (ERIBON, LÉVI-STRAUSS, 1990, p.171).

A obra analisada, então, não se pretende generalista, mas complexa. Ao elaborar estruturas míticas relacionais, o autor não atua reduzindo ou descontextualizando os mitos, mas revelando pontos de convergência e ligações entre estes. Elementos "naturais" como água, fogo, vida e morte são experimentados por personagens como animais, pessoas e espíritos e em cada mito trocam de lugar e de significado, mas não aleatoriamente. Indicam, de tal maneira, que o nomadismo pode ter disseminado uma forma de pensamento similar, porém não idêntica, entre as etnias indígenas das Américas.

\section{NATUREZA E CULTURA REVISITADAS}

Eduardo Viveiros de Castro (1996) propõe uma significação sofisticada para entender a relação entre Natureza e Cultura de povos ameríndios e a diferença de visão entre estes e a visão do que seja Natureza e Cultura para o pensamento ocidental, moderno e científico. A argumentação deste autor pode ser reduzida a seguinte equação:

\begin{tabular}{|c|c|}
\hline $\begin{array}{c}\text { Perspectivismo ameríndio } \\
\text { "multinaturalismo" }\end{array}$ & $\begin{array}{c}\text { Pensamento ocidental } \\
\text { "multiculturalismo" }\end{array}$ \\
\hline $1 \mathrm{C} / \mathrm{nN}$ & $\mathrm{nC} / 1 \mathbf{N}$ \\
\hline
\end{tabular}

Tabela 1: Resolução matemática a respeito da argumentação de Castro (1996) sobre a diferença entre o perspectivismo ameríndio e o pensamento ocidental. 
Nessa equação, o pensamento ocidental veria uma multiplicidade de culturas e uma só natureza, que poderia se referir à natureza humana ou ao cosmos, ao mundo "natural"; e, a teoria indígena se referiria a uma cultura, humana, de onde se extraem várias "roupas" ou "corpos", que seriam as múltiplas naturezas.

Os mitos de O cru e o cozido são diferentes perspectivas de uma mesma realidade colocadas em comparação. Para Viveiros de Castro (1996), ‘[...] se o multiculturalismo ocidental é o relativismo como política pública, o xamanismo perspectivista ameríndio é o multinaturalismo como política cósmica" (VIVEIROS DE CASTRO, 1996, p. 120). Este autor coloca que, enquanto o evolucionismo e o cristianismo acreditam que o ser-humano é a última etapa, mais complexa e evoluída, conforme o primeiro, e, a última criatura a ser moldada por Deus, segundo o último, sendo ambos cânones do pensamento ocidental e científico; a filosofia indígena, ou, o perspectivismo ameríndio como denomina o autor, vê o ser-humano como o primeiro a existir e se nos propormos a ler as mitologias ameríndias, essas nos mostrando o humano enquanto ser primeiro, origem de tudo, que se modifica, se transforma, no desenrolar das narrativas, em animais, plantas, astros (como, por exemplo, as plêiades, em O cru e o cozido) e, em alguns casos, espíritos. É interessante lembrar as palavras de Viveiros de Castro (1996, p. 17):

\begin{abstract}
Tipicamente, os humanos, em condições normais, vêem os humanos como humanos, os animais como animais e os espíritos (se os vêem) como espíritos; já os animais (predadores) e os espíritos vêem os humanos como animais (de presa), ao passo que os animais (de presa) vêem os humanos como espíritos ou como animais (predadores). Em troca, os animais e espíritos se vêem como humanos: apreendem-se como (ou se tornam) antropomorfos quando estão em suas próprias casas ou aldeias, e experimentam seus próprios hábitos e características sob a espécie da cultura - vêem seu alimento como alimento humano (os jaguares vêem o sangue como cauim, os mortos vêem os grilos como peixes, os urubus vêem os vermes da carne podre como peixe assado etc.), seus atributos corporais (pelagem, plumas, garras, bicos etc.) como adornos ou instrumentos culturais, seu sistema social como organizado do mesmo modo que as instituições humanas (com chefes, xamãs, festas, ritos etc.).
\end{abstract}

Essa dinâmica, de várias lentes apreendendo a realidade, ou as realidades, é nítida em $\mathrm{O}$ cru e o cozido. Nesta obra, não só há a revelação de várias interpretações míticas correspondentes as diferenças étnicas, mas também em cada mito os personagens vêem a realidade de um ponto de vista particular. 
Portanto, os xamãs/pajés aparecem como demiurgos, assim como muitos dos anteriormente "nativos" se tornaram na atualidade antropólogos, uma atividade anteriormente reservada a "sábios" e "exploradores" — segundo Lévi-Strauss em A crise moderna da Antropologia (1962) — e que, agora, interessa a todos(as), em escala planetária. Para Lévi-Strauss, a condição de existência da antropologia e da etnologia seria que pessoas de etnias diversas se interessassem pelos métodos e conceitos antropológicos e os utilizassem para também permearem a ciência com as suas perspectivas da realidade de outros povos. Neste fazer, o futuro da ciência não iria divergir do pensamento selvagem, mas sim convergir a ele.

Entretanto, Lévi-Strauss, resigna-se ao escrever: '[...] os Ocidentais não conseguirão nunca - a não ser talvez como farsa - desempenhar o papel de 'selvagens' em relação àqueles que eram anteriormente dominados por eles". Este é um dos desafios da antropologia, das artes e da ciência em geral: pensar em relações que põem em questão o humano-humano-ambiente.

Não obstante, Renato Sztutman (2009) questiona, parafraseando LéviStrauss, se o dualismo natureza/cultura é bom para pensar as sociocosmologias ameríndias. Este autor considera que o dualismo não é bom para pensar as sociocosmologias ameríndias, porque este é um paradigma do pensamento moderno, está na base da ciência moderna e polemiza ao afirmar que os aparatos conceituais produzidos na modernidade são insuficientes, inclusive, para representar a própria sociedade complexa. Sobre tal ponto de vista, acredita-se que o paradigma natureza-cultura é uma preocupação da ciência moderna, mas não uma invenção dessa, haja vista a intensa produção científica e filosófica que pautou debates desde a época de Aristóteles.

Sztutman (2009) também lembra que as populações indígenas transformam ativamente o ambiente em que vivem e não podem ser reduzidas a sujeitos passivos diante de uma natureza intocável e afirma que, para manter o termo ocidental "natureza" ao se falar de pensamento ameríndio deve-se lembrar que "natureza" para uns não é a mesma "natureza" de outros, e isso conduz a uma série de "equívocos". Um deles, segundo o autor, é imputar aos povos ameríndios uma vocação ecológica, de inclinação conservacionista.

Sobre essa última questão, sabe-se que as etnias indígenas sul-americanas conceitualizam as relações que estabelecem de forma diferente que a noção 
calcada na ciência moderna, e isto traz conseqüências menos destrutivas para "o mundo natural", do que o caminho aberto pela sociedade moderna, promotora da Revolução Industrial. Apesar da relação natureza-cultura construída pelos povos indígenas causar menos impacto no ambiente, ela não foi lapidada por uma militância a favor da "preservação da natureza", e sim se constituiu a partir de uma dimensão ontológica dessas mesmas sociedades, que se denominam como "tradicionais", e que, em realidade, estão em permanente transformação.

\section{A CONSCIÊNCIA ECOLÓGICA DE LÉVI-STRAUSS E A INDÚSTRIA CULTURAL HOJE: O AMBIENTE COMO "O OUTRO"}

Ao comparar a obra O cru e o cozido com a recente produção da indústria cultural Avatar, de James Cameron (2009) ${ }^{2}$, observa-se que o filme trata de questões que envolvem a percepção e reflexão da natureza-cultura, e como as transformações cunhadas pela humanidade podem ser perniciosas, inclusive para a sua própria perpetuidade. Apesar de que na maioria das entrevistas concedidas pelo seu autor terem enfatizados os aspectos de inovação tecnológica que o filme contém, é imprescindível analisá-lo também sob uma ótica da visão do comportamento humano que se revela implícita e explícita na temática desta produção audiovisual.

A história do filme se passa no século XXII, na lua Pandora - um satélite "natural" do planeta Polifemo que gira ao redor de uma estrela da constelação Alfa Centauro - e relata a trajetória de um soldado terrestre com paraplegia que transforma sua visão de "cosmos" ao entrar em contato (por meio de seu corpo adaptado via transformação transgênica em laboratório) com uma sociedade diferente da que conhecia, física e moralmente, e muda de objetivos ao constatar que fazia mais sentido pensar e agir conforme aquela sociedade, que no filme denomina-se Na'vi. Apesar dos clichês - sendo o maior deles a conversão do herói masculino por meio do amor a uma personagem feminina — o filme se posiciona politicamente quando o assunto é ambientalismo. Entretanto, torna-se contraditório se pensarmos que a sociedade da técnica, da tecnologia e da ciência cartesiana é

\footnotetext{
${ }^{2}$ Aqui não gostaria de entrar na polêmica levantada por veículos de comunicação, a qual destaca que tal obra cinematográfica teria sido plágio de outras obras impressas de ficção científica. Tal discussão não cabe neste manuscrito.
} 
que construiu os meios para a realização do filme. Se a reflexão puder acontecer de forma dialética, então este conflito é benéfico e auxiliará na problematização desta discussão.

Ao expor uma história de encontro entre duas civilizações, uma nativa e outra que tem o intuito de explorar aquele espaço de forma lucrativa, o filme reproduz o momento de nossa história das grandes navegações, no qual a Europa lança-se a mares inóspitos e encontra-se com "os outros", estabelecendo o estranhamento mútuo. As diferenças tecnológicas e de objetivos e crenças são profundas e o que prevalece é a dominação e o genocídio. Não seria por acaso que Lévi-Strauss confessa a Eribon: “(...) não somente para mim, a vocação etnológica talvez tenha sido mesmo um refúgio contra uma civilização, um século, em que a gente não se sente à vontade." (1990, p.90).

Interessante que, apesar de Lévi-Strauss dizer que não se sentia à vontade em seu tempo, fez reflexões inovadoras sobre natureza e cultura, que jamais subordinam a natureza à cultura e que, ao mesmo tempo, não confere valor supremo à natureza. Em O cru e o cozido, na terceira parte intitulada Fuga dos sentidos, o antropólogo lembra que os indígenas do Brasil Central são originados de agricultores primitivos que não poderiam - apenas com machados de pedra derrubar as árvores da floresta. Eles têm de recorrer ao fogo, mantido durante dias ao pé dos troncos, até que a madeira viva se tenha aos poucos consumido e ceda ao golpe de ferramentas rudimentares.

Lévi-Strauss escreve que “O fato de esse 'cozimento' pré-culinário da madeira viva levantar um problema lógico e filosófico, resulta da proibição de cortar a madeira 'viva' para fazer lenha." (2004a, p.181-182). É sabido que qualquer cultura tem um impacto mais ou menos relevante no ambiente em que se desenvolve. $A$ coletividade responde a este impacto com suas narrativas míticas ou científicas, elabora de alguma forma esta relação, a (re)significa. A diferença está nos aspectos centrais que, numa cultura antropocêntrica, concentram-se na perpetuidade da humanidade enquanto espécie e numa cultura cosmocêntrica seria a perpetuidade de várias espécies e isto enquanto objetivo primordial. Quando Lévi-Strauss coloca vários mitos em comunicação, que correspondem a etnias diferentes, ele relativiza esse objetivo etnocêntrico e garante um pensamento mais cosmocêntrico da realidade ameríndia. No filme Avatar, o ambiente (a natureza de acordo com o senso comum) não é apenas palco, cenário afônico onde as cenas se desenrolam, mas 
também é protagonista de uma luta pela perpetuidade das espécies que habitam aquele local do espaço.

Pode-se vincular esta questão de alteridade ao que Félix Guatarri (2001) chama de ecosofia que, segundo ele, consiste na interação dos três registros ecológicos: o do meio ambiente, o das relações sociais e o da subjetividade humana. E, também, podem-se retomar palavras de Edgar Morin (2007) sobre a cidadania terrestre, conceito que alude ao se referir a necessidade dos seres humanos de abandonar radicalmente o projeto conquistador (proposto por teóricos como Descartes) e trabalhar em pró da co-regulação da biosfera terrestre. A antropoética da era planetária conceituada por Morin (2007) envolve a compreensão da diversidade de pensamentos sobre o que seja natureza-cultura entendida no discurso de Castro (1996). E, esse desdobramento só foi possível na história das Ciências Humanas com trabalhos que ultrapassaram as fronteiras epistemológicas, como Mitológicas de Lévi-Strauss.

Desdobramento este que não se retém nos bancos das universidades, mas chega aos bancos das salas de cinema, irradia-se descentralizado, como diria Hall (1998), para o cotidiano latente das grandes cidades. Em Avatar, há o ponto de vista que se liga ao corpo. Em O cru e o cozido, os mitos revelam transformações dos seres dadas a partir dos diferentes pontos de vista. Os mitos são discursos da sociedade sobre si mesma, Lévi-Strauss faz estes discursos se encontrarem, assim como acontece o encontro de duas sociedades com diferentes interesses e narrativas em Avatar.

Sem hierarquizar culturas, Lévi-Strauss (1996) coloca que as sociedades ditas primitivas estão na história e seu passado é tão antigo quanto o passado de outras sociedades ditas complexas, e que, no decorrer de milênios, elas se especializaram em setores diferentes - por exemplo, com relação aos setores privilegiados pela sociedade européia, que avançou perante a tecnologia e a ciência. Quanto a estes setores, os ameríndios permaneceram próximos a sociedades antigas, o que não quer dizer que em outros setores se distanciaram mais do passado do que as sociedades modernas.

O dilema real é parecido com o da ficção e coloca em pólos antagônicos duas concepções de mundo como as da sociedade ocidental (científica) e as sociedades ameríndias (mitológica), como explicita Castro (1996, p.124): 
[...] em lugar de precisarmos provar que eles são humanos porque se distinguem do animal, trata-se agora de mostrar quão pouco humanos somos nós, que opomos humanos e animais de um modo que eles nunca fizeram: para eles, natureza e cultura são parte de um mesmo campo sociocósmico. Os ameríndios não somente passariam ao largo do Grande Divisor cartesiano que separou a humanidade da animalidade, como sua concepção social do cosmos (e cósmica da sociedade) antecipa as lições fundamentais da ecologia, que apenas agora estamos em condições de assimilar.

Segundo Lévi-Strauss em entrevista concedida a Castro (1998) a antropologia é obra de uma sociedade sobre outras sociedades e a questão não é a de se elas estão inseridas ou não na história mundial, mas sim, de que elas possuem sua própria história, suas experiências humanas e os significados destas experiências.

Dessa forma, uma análise que pretende discorrer sobre culturas diversas e tomando a natureza como "o outro", deve tomar cuidado para não resvalar no equívoco de tomar a cultura — que se relaciona de forma mais "saudável" com o ambiente — como mais próxima do natural do que do selvagem.

A questão está na relação que as culturas têm com "o outro" ambiente, se são de reciprocidade ou artificialidade e não se uma cultura é mais selvagem/originária/natural que a outra. Erro esse que pode se incorrer ao tentar pensar no filme Avatar relacionando a semelhança que deram aos personagens de uma das culturas em contato, com a aparência da fauna de nossa biosfera (por exemplo, a cauda e as orelhas). Mais do que a aparência pode-se fazer conexão com a realidade atual no tocante ao estranhamento das culturas e é interessante notar que os sobreviventes do embate foram aqueles que conseguiram se colocar no lugar do "outro", conseguiram ver "o que o outro vê", como um xamã ou um antropólogo.

Voltando ao Cru e o cozido, Lévi-Strauss finaliza comparando à onomatopéia e à caricatura o pensamento mítico, pois este "só aceita a natureza com a condição de poder repeti-la" (2004a, p.386). Ou seja, a vocação de metáfora do mito é interessante para pensar a antropoética necessária à relação com "o outro" natureza. Lévi-Strauss constrói um ambientalismo menos idealizado que o costumeiro e apóia-se nas narrativas do sujeito humano para relativizar a ideia de progresso e dizer que a humanidade não deve se reduzir a uma só forma de sociabilidade se quiser continuar se relacionando com o ambiente em que vive. Deve, assim, valorizar o ambiente como sujeito, sem tutelá-lo, assim como aprendeu a fazer com outros humanos, através do desenvolvimento da antropologia e da 
valorização de pensamentos que antes eram periféricos, como o pensamento ameríndio.

\section{CONSIDERAÇÕES FINAIS}

A atualidade da obra Mitológicas de Lévi-Strauss não se traduz pelo método empregado ou pelo objeto de pesquisa. Ela é revelada no conjunto da obra e nas inúmeras possibilidades de reflexão que se descortina ao ler a tetralogia. Pode ser tratada como uma pesquisa científica, uma obra de arte, uma reunião criativa de narrações coletivas construídas em diversos contextos étnicos. É interdisciplinar porque envolve aspectos lógico-matemáticos, linguísticos, musicais, antropológicos, estéticos e medicinais. É complexa porque ao invés de generalizar e reduzir traz à tona possibilidades reflexivas sobre natureza-cultura e as relações de alteridade entre espécies, que são necessárias para alterar beneficamente o modo como a humanidade se insere hoje em diferentes ecossistemas.

Nesse sentido, O cru e o cozido é um livro que não apreende os mitos das etnias da América do Sul em arcabouços, isto é, estruturas rígidas e permanentes. Ao contrário, Lévi-Strauss faz uma "amarração mitológica", tal como se faz, nestas sociedades: redes, habitações, móveis ou balaios. O autor se apóia em traduções e trabalhos de campo de outros antropólogos, porque o objetivo de seu trabalho não é filológico, mas de interpretação. Ele quer indicar um caminho para a reflexão macrossocial, para a interpretação das construções mitológicas humanas.

Algo que se evidencia de toda esta monumental empreitada é a capacidade de escrever com total clareza se contrapondo a uma visão de "dominação" da natureza que pautou diversos intelectuais ao longo da história do pensamento e da ciência, de Aristóteles a Marx. Quando Lévi-Strauss mostra a diluição de personagens humanos e não-humanos, contida no pensamento mítico ameríndio, ele se aproxima de propostas recentes da indústria cultural, como a do filme Avatar. Propostas que mostram o paradoxo em que vive a sociedade planetária, refém das desigualdades sociais e do lixo material produzido ao tentar "vencer" o ambiente a qualquer custo.

Em tal contexto, as sociedades ditas complexas têm grande dificuldade em se contrapor à ideia de natureza como algo inato, exterior a ação humana, sendo esta 
visão das relações entre seres-humanos e não-humanos superada pelas nações indígenas sul-americanas que, ontologicamente, vêem humanos e não-humanos com vínculos bem mais entrelaçados do que a visão moderna poderia conceber.

Caminhos lançados na comunidade acadêmica ou por movimentos sociais e centros de pesquisa algumas vezes encontram eco na própria indústria cultural que ressoa estes conflitos em histórias aparentemente superficiais. Obras como "O cru e o cozido" condensam de forma criativa mitologias que talvez só agora possam ser pensadas com maior relevância, e, dessa maneira, rever conceitos modernos e oposições binárias e desvelar a crise inter-étnica e inter-espécies que polemizam as relações existentes em um planeta conhecido entre os seres-humanos como Terra. 


\section{REFERÊNCIAS}

CAMERON, James. Avatar. [filme-vídeo]. EUA/Reino Unido, Fox Filmes do Brasil (distribuição), 2009. 166 min.

CASTRO, Eduardo Viveiros de. Lévi-Strauss nos 90 a antropologia de cabeça para baixo. Revista Mana, v.4, n.2, p.119-126, 1998.

CASTRO, Eduardo Viveiros de. Os pronomes cosmológicos e o perspectivismo ameríndio. Revista Mana. v.2, n.2, p.115-144, 1996.

ERIBON, Didier; LÉVI-STRAUSS, Claude. De perto e de longe. Tradução Léa Mello e Julieta Leite. Rio de Janeiro: Nova Fronteira, 1990.

FOSTER, Hal. Belleza compulsiva. Tradução Tâmara Stuby. Buenos Aires: Adriano Hidalgo, 2008.

GUATARI, Félix. As três ecologias. Tradução Maria Cristina Bittencourt. $11^{\mathrm{a} e d .}$ Campinas: Papirus Editora, 2001.

HALL, Stuart. A identidade cultural na pós-modernidade. Tradução Tomaz Tadeu da Silva e Guacira Lopes Louro. Rio de Janeiro: DP\&A, 1998.

LÉVI-STRAUSS, Claude. A crise moderna da antropologia. Revista de Antropologia, v.10, n.1 e 2, 1962.

LÉVI-STRAUSS, Claude. Antropologia Estrutural 2. $5^{\text {a }}$ Ed. São Paulo: Tempo Brasileiro, 1996.

LÉVI-STRAUSS, Claude. Mito e Significado. Tradução Antônio Marques Bessa. Coletivo Sabotagem, 1978.

LÉVI-STRAUSS, Claude. Mitológicas 1: O cru e o cozido. Tradução Beatriz Perrone-Moisés. São Paulo: Cosac \& Naify, 2004a.

LÉVI-STRAUSS, Claude. Tristes Trópicos. Tradução Rosa Freire D’aguiar. São Paulo: Companhia das Letras, 2004b. 
LÉVI-STRAUSS, Claude. O pensamento selvagem. Tradução Tânia Pellegrini. $8^{\mathrm{a} e d .}$ Campinas: Papirus, 2008.

MARQUES, José Oscar de Almeida. Rousseau, fundador das ciências do homem? In: MARQUES, J.O.A. (org.). Verdades e mentiras: 30 ensaios em torno de JeanJacques Rousseau. Ijuí: Ed. UNIJUÍ, 2005. p.249-272.

MOISÉS, Massaud. Dicionário de Termos Literários. 1 ed. São Paulo: Cultrix, 1974.

MORIN, Edgar. Educação e complexidade: os sete saberes e outros ensaios. Tradução Edgard de Assis Carvalho. 4 ed. São Paulo: Cortez Editora, 2007.

PASSETTI, Dorothea Voegeli. Lévi-Strauss, Antropologia e Arte: minúsculo incomensurável. EDUC/EDUSP: São Paulo, 2008.

PERRONE-MOISÉS, Beatriz. Claude Lévi-Strauss, aos 90. Revista de Antropologia: São Paulo, v.42, n.1-2, p. 9-25, 1999.

SAÉZ, Oscar Calávia. Lévi-Strauss, Ciência e Renúncia. Revista Campos, n.9, v.2, p.9-22, 2008.

SZTUTMAN, Renato. O espírito na América. Novos estudos - CEBRAP, n.72, p. 209-218, 2005.

SZTUTMAN, Renato. Natureza \& Cultura, versão americanista - um sobrevôo. Aula proferida durante o concurso para professor de etnologia indígena da USP. Disponível em <epifenomenos.blogspot.com/2009/08/natureza-cultura-xequemate.html>. Acessado em 25 mai. 2010.

Artigo:

Recebido em: 23/06/2010

Aceito em: 27/09/2010 